\title{
Epigenetic regulation of Hox gene activation: the waltz of methyls
}

\author{
Natalia Soshnikova ${ }^{1}$ and Denis Duboule ${ }^{1,2 \star}$
}

\begin{abstract}
Summary
Genetic studies have revealed that the antagonistic interplay between PcG and TrxG/MLL complexes is essential for the proper maintenance of vertebrate Hox gene expression in time and space. Hox genes must be silenced in totipotent embryonic stem cells and, in contrast, rapidly activated during embryogenesis. Here we discuss some recently published articles ${ }^{(1-4)}$ that propose a novel mechanism for the induction of Hox gene transcription. These studies report a new family of histone demethylases that remove $\mathrm{H} 3 \mathrm{~K} 27 \mathrm{me} 3 / \mathrm{me} 2$ repressive marks at Hox promoters during differentiation of stem cells. Though the overall importance of these enzymes for proper embryogenesis was demonstrated, their precise role in Hox gene epigenetic regulation during development still remains to be firmly established. BioEssays 30:199-202, 2008. (C) 2008 Wiley Periodicals, Inc.
\end{abstract}

\section{Introduction}

Chromatin structure is usually defined by a set of posttranslational modifications of histones, such as methylation, acetylation, phosphorylation and ubiquitination. ${ }^{(5)}$ Recently, genome-wide studies of such histone modifications have suggested that chromatin states control the specification and maintenance of cell identity. In particular, the methylation of either H3K4, catalyzed by trithorax group (trxG) proteins, or H3K27, by Polycomb group (PcG) proteins, play important roles in dividing the genome into transcriptionally active and silent areas, respectively. ${ }^{(6-9)}$

\section{Epigenetic control of Hox genes activation?}

PcG and trxG proteins were originally identified via genetic studies in the fruit fly as negative and positive regulators of the BX-C homeotic gene cluster. ${ }^{(10)}$ In vertebrates, Hox genes are also clustered and encode transcription factors essential

\footnotetext{
${ }^{1}$ National Research Centre 'Frontiers in Genetics', Department of Zoology and Animal Biology, University of Geneva, Geneva, Switzerland.

${ }^{2}$ School of Life Sciences, Ecole Polytechnique Fédérale, Lausanne, Switzerland

${ }^{*}$ Correspondence to: Denis Duboule, National Research Centre 'Frontiers in Genetics', Department of Zoology and Animal Biology, University of Geneva, Sciences III, Quai Ernest-Ansermet 30, 1211 Geneva 4. E-mail: denis.duboule@zoo.unige.ch

DOI 10.1002/bies.20724

Published online in Wiley InterScience (www.interscience.wiley.com).
}

for proper embryonic development, ${ }^{(11)}$ as shown by slight variations in HOX protein combinations, which usually lead to homeotic transformations, involving either duplication or loss of body structures. Therefore, the distribution of these proteins ought to be precisely orchestrated, a task mostly achieved at the transcriptional level. One particularly interesting level of regulation, in this context, is the correspondence that is observed between the genes' respective locations, within their clusters, and their time and places of activation. Genes at the $3^{\prime}$ end of the clusters are activated first, early on and in the most-anterior parts of the developing embryo, whereas genes located at progressively more $5^{\prime}$ genomic positions are activated subsequently and in more posterior areas. ${ }^{(11)}$

Amongst the candidate pathways involved in the control of this progressive transcriptional activation, all trans retinoic acid (RA) was reported to induce Hox gene transcription in a collinear manner, from the $3^{\prime}$ to the $5^{\prime}$ part of the gene cluster, in differentiating human EC cells. ${ }^{(12)}$ Retinoic Acid Response Elements (RARE) were subsequently identified in the vicinity of several $3^{\prime}$-located Hoxgenes, such as Hoxa1 and Hoxb1. (13) In mice, depletion of RA or removal of the RARE lying $3^{\prime}$ of Hoxa1 resulted in a delay in gene activation. Other molecules important for the anterior-to-posterior (AP) patterning of the embryo have been implicated in Hox gene activation, such as FGF, WNT and CDX, ${ }^{(14)}$ even though formal demonstrations remain to be shown.

Once correctly established, Hox expression domains must be maintained, at least for the duration of their patterning functions. At least part of this transcriptional cellular memory appears to rely upon PcG and trxG gene products. ${ }^{(10,15)} P c G$ and TrxG come as multi-proteins complexes, containing both histone methyltransferase activity, as well as proteins binding methylated histone lysine residues. Mutations in PcG genes lead to ectopic Hox gene expression and consequent posterior homeotic transformations in both Drosophila and vertebrates. To mediate the necessary long-term repression of Hox genes, components of the Polycomb Repressive Complex 2 (PRC2) tri-methylate H3K27 (me3). ${ }^{(16)}$ Recruitment of PRC1 members to $\mathrm{H} 3 \mathrm{~K} 27 \mathrm{me} 3$ inhibits chromatin remodeling activity and promotes condensation of chromatin structure. ${ }^{(17)}$ Moreover, PRC1 ubiquitinates H2A, a step that seems essential for Hox silencing. ${ }^{(18)}$ Recently, genome-wide studies have revealed that, in embryonic stem (ES) cells, components of both PRC1 and PRC2 are recruited to the promoters of many transcription 
factors involved in development and differentiation. ${ }^{(9,19-23)}$ Remarkably, both PRC2 and H3K27me3 were not detected at promoters, but instead were distributed along approx. $100 \mathrm{~kb}$ large domains within all four Hox gene clusters. ${ }^{(9,22)}$ Analyses of PRC2 mutants further demonstrated that this complexdependent methylation of $\mathrm{H} 3 \mathrm{~K} 27$ is required for repressing Hox genes in ES cells. ${ }^{(9)}$ In Drosophila screens for modifiers that suppress the homeotic phenotype displayed by PcG mutants led to the identification of $\operatorname{trx} G$ genes. ${ }^{(10)}$ In trx or MII mutants, early expression of Hox genes is properly initiated, yet it is subsequently not faithfully maintained. ${ }^{(10,24,25)}$ Analysis of Drosophila trxG/PcG double mutants indicated that the activity of TrxG/MLL complexes is required to prevent PcG-mediated silencing of transcribed Hox genes. ${ }^{(26)}$ TrxG/ MLL proteins complexes catalyze the trimethylation of H3K4, which is generally associated with active transcription. ${ }^{(10,15)}$ Accordingly, H3K4me3-modified nucleosomes are specifically enriched at the promoters of active genes. ${ }^{(6-8,27,28)}$

Interestingly, Hoxgene clusters display a peculiar pattern of $\mathrm{H} 3 \mathrm{~K} 4 \mathrm{me} / \mathrm{me} 2$ marks in differentiated cells, covering large regions with several genes, a situation that correlates quite well with the high intergenic transcriptional activity reported within these clusters. ${ }^{(6,29)}$ Furthermore, in ES cells, Hox gene promoters often display both H3K4me3 and H3K27me3 marks, and such regions containing both repressive and activating chromatin modifications were referred to as 'bivalent domains'. ${ }^{(7)}$ In stem cells, these bivalent domains may keep Hox genes poised for activation. But how do Hox genes become transcriptionally activated during ES cells differentiation or embryonic development? Trimethylation of H3K27 is a rather stable modification, which could be progressively lost in the absence of PRC2, along with cell divisions. ${ }^{(30)}$ However, studies in ES cells indicated that changes in chromatin associated with Hox gene activation are likely to occur promptly, calling for a more active process, for instance involving an appropriate demethylase activity.

\section{Novel histone demethylases}

In this context, several research groups recently identified enzymes responsible for demethylation of H3K27me3 and me2 and addressed their potential roles during stem cell differentiation and animal development. ${ }^{(1-4)}$ Agger and colleagues $^{(1)}$ report on UTX and JMJD3, two human proteins belonging to a larger family, evolutionary conserved from Caenorhabditis elegans to human. These proteins contain a JmjC peptide sequence, which was described as a catalytic domain for other histone demethylases. ${ }^{(31)}$ The structure of the JmjC domain defines both their phylogenetic group and substrate specificity. ${ }^{(1,32)}$ These proteins add to other subfamilies of histone demethylases reported to date and acting specifically on H3K4, H3K36, H3K9 and H3R2/H4R3. ${ }^{(33)}$

When JMJD3, UTX or UTY proteins were used in histone demethylation assays in vitro with either synthetic $\mathrm{H} 3$ peptides, or bulk histones as substrates, both UTX and JMJD3 specifically demethylated H3K27me3 and, though to lesser extent, H3K27me2. In contrast, UTY, which is highly homologous to UTX, did not show any enzymatic activity. ${ }^{(3)}$ In addition, ectopic expression of JMJD3 in different cell lines decreased the amount of trimethylated H3K27, while concomitantly increasing its mono-methylated form. ${ }^{(3)}$ It is noteworthy that a genome-wide study associated H3K27me1 modification with transcriptional activation. ${ }^{(6)}$ Consistently, depletion of UTX or JMJD3 proteins using short hairpin (sh)RNAs led to a global increase of H3K27me3 levels. ${ }^{(1)}$ Could these demethylases be involved in Hox genes regulation? Chromatin immunoprecipitation (ChIP) assays revealed that several Hox genes are indeed direct targets of UTX and JMJD3, in a variety of cell lines. (1,2,4) Furthermore, Lan and colleagues ${ }^{(3)}$ performed ChIP on chip analysis (ChIP followed by hybridization to ultra-dense tilling microarrays) on all four human HOX clusters, using ES cells and two primary fibroblast cell lines as sources of materials. Combined ChIP data indicate that UTX (and probably JMJD3) selectively occupies transcription start sites of the target genes in a celltype-specific manner, such that UTX and JMJD3 positively correlates with the transcriptional activity of the promoters. Accordingly, depletion of these proteins using either (si)RNAs or (sh)RNAs, elevated the level of H3K27me3 marks at the start sites of target Hox genes, concomitantly with their repression.

The analysis of these few Hox loci thus suggested that UTX and/or JMJD3 are required for the maintenance of Hox genes expression in differentiated cells. However, based on ChIP on chip data, which revealed all binding sites within the four HOX clusters by using a specific cell type, Lan and colleagues ${ }^{(3)}$ did not observe any correlation between UTX binding and transcriptional activity. It is possible that the recruitment of cofactors, together with UTX, is necessary for transcriptional activation and it was shown that UTX and JMJD3 can interact with components of the MLL2/3 complexes. ${ }^{(2,4,34)}$ This physical association between enzymes removing the H3K27me3 repressive mark, on the one hand, with protein complexes promoting the deposition of the active H3K4me3 mark, on the other hand, suggests that both activities are required for a rapid response of target genes.

In order to investigate the function of UTX in the activation of Hox gene expression during cellular differentiation, Agger et al. and Lee et al. ${ }^{(1,4)}$ treated human embryonal carcinoma (EC) NT2/D1 cells with retinoic acid to induce differentiation. Using a ChIP assay, they showed that components of the MLL2 complex were initially recruited at the promoters of the most anterior $\mathrm{HOXA}$ and $\mathrm{HOXB}$ genes, with $\mathrm{H} 3 \mathrm{~K} 4$ becoming trimethylated. Progressive engagement of UTX and concomitant loss of PRC2 and H3K27me3 marks from the promoters resulted in a rapid activation of these genes. ${ }^{(1,4)}$ In this context, UTX seems to be important for activating Hox genes, as a loss 
of UTX expression led to a strong decrease in $H O X B 1$ transcription. ${ }^{(1)}$ While it is possible that protein members of the Utx family have a more general function in the regulation of Polycomb repressed genes, ${ }^{(2)}$ it remains unknown whether UTX, which was found only at promoters, may also remove H3K27me3 modifications from the coding and intergenic regions during cellular differentiation. H3K27me3 domains can indeed be $100 \mathrm{~kb}$ large, encompassing several genes within HOX clusters. ${ }^{(9,22)}$ ChIP-on-chip analysis, by using homogenous populations of progressively differentiating cells, at several time points, would be informative in this respect.

The role of UTX and JMJD3 in the resolution of 'bivalent domains' into an active state during stem cells differentiation is exemplified by $B m p-2$, a gene encoding a signaling molecule necessary for the differentiation of pluripotent cells. ${ }^{(2)}$ When in a repressed state, its promoter is associated with both H3K4me3 and H3K27me3 modifications. Upon differentiation of macrophage precursor cells, the binding of JMJD3 to the $B m p-2$ transcription start site, and concomitant decrease in the level of trimethylated $\mathrm{H} 3 \mathrm{~K} 27$, is essential for gene activation, whereas the level of $\mathrm{H} 3 \mathrm{~K} 4 \mathrm{me} 3$ could remain unchanged. It was postulated that the dominant effect of H3K27me3 over H3K4me3 modification, in a bivalent histone domain, silences a specific set of genes to maintain ES cells totipotency. ${ }^{(7)}$ Consistently, ChIP on chip analysis revealed an absence of UTX binding at the HOX clusters in ES cells. ${ }^{(3)}$

\section{Functional relevance in a developmental context}

The approaches described above, as well as previously published work $^{(29)}$ make use of either established or primary cell lines, which introduces two major problems. The first one is technical and has to do with the homogeneity of cells within a given population hence the final results may integrate several distinct cellular states. The second problem is the heuristic values of such in vitro systems, i.e. to what extent they can be used as an illustration of what happens during early development. There, the situation is unclear, to say the least, and one should perhaps be careful in extrapolating too rapidly data from fibroblasts to those few cells that start to activate Hox genes in a time sequence, during early gastrulation. Functionally significant approaches, in this context, are hampered by the low amount of available cells to look at and their heterogenous distribution.

In an effort to elucidate the function of Utx family members during embryogenesis, Agger and colleagues ${ }^{(1)}$ use a loss-offunction approach in $C$. elegans. They report that either the mutation, or RNA interference-based depletion of the JMJD3 orthologue F18E9.5, leads to aberrant gonadal development. While this phenotype convincingly demonstrates the requirement of this demethylase for the development of gonads, it does not make an obvious link with Hox gene regulation in the nematode. In contrast, phenotypes associated with Hox gene mis-expression were not detected in this experimental setting.

The arguments brought by Lan and colleagues ${ }^{(3)}$ to claim that a zebrafish UTX protein regulates posterior development by acting upon Hox gene regulation are not utterly convincing either. By using injection of antisense morpholino oligonucleotides, some severe defects were indeed scored in the developing somites and notocord, as well as in hematopoetic tissues. In contrast, development of the head, the 'thoracic' region and the most-posterior structures (the tail) remained unaffected. $^{(3)}$ Even though the analysis of zUTX1 morphants seemed to indicate a slight posterior shift of the hoxc8a and hoxd9a expression domains, a general role of UTX in the regulation of Hox genes during zebrafish development cannot be inferred from these results. Firstly, the presence of UTX at Hox promoters during zebrafish development was not examined. Most importantly, the very modest decreases in Hox gene expression reported by Lan and colleagues ${ }^{(3)}$ in their morphants (at worst, the fish still express its Hox genes at 75 percent of the wild-type amount) cannot explain the described phenotype, considering the vast amount of literature reporting functional studies of Hox genes in a variety of animal models.

\section{Conclusions}

The recent papers discussed above report a new family of H3K27me3/2 demethylases. This is arguably an interesting new piece added to the puzzle of epigenetic gene regulation. The recruitment of UTX and JMJD3 demethylases to the promoters of Hox genes seem to be required either for their transcriptional activation during differentiation of stem cells, or for the expression maintenance in lineage-committed cells. UTX and JMJD3 interact with components of the MLL2/3 complexes. Moreover, depletion of either zUTX1, or of WDR5, an essential component of the MLL complex, caused similar developmental defects in both zebrafish and Xenopus embryos, ${ }^{(3,35)}$ suggesting that activities of UTX and MLL complex may be coupled during development. It has been proposed that the deposition of active mark by the MLL complex, concomitantly with the removal of repressive marks by UTX/JMJD3 at a target promoter could be a mechanism for activation of gene transcription. ${ }^{(1)}$ Conversely, mutual activities of PRC complexes and H3K4me3 demethylases could efficiently silence target genes.

While the reported loss-of-function studies in fish and nematodes show that UTX and JMJD3 interact with important developmental pathways, during embryogenesis, a clear involvement of Hoxgenes in those affected processes remains to be convincingly demonstrated. This is also illustrated by the analyses of mutant phenotypes, which indicate that UTX and JMJD3 regulate expression of other 'developmental' genes. For instance, examination of UTX targets in ES cells reveal an 
enrichment for genes encoding olfactory receptors, ${ }^{(3)}$ which are expressed only in differentiated olfactory neurons. ${ }^{(36)}$ Therefore, while these studies re-enforce the hypothesis that the collinear Hox genes activation process relies in part upon progressive chromatin 'opening', (37) a formal demonstration will have to await the use of more physiologically relevant starting material, such as those few cells where such an elusive transcriptional mechanism initially operates.

\section{References}

1. Agger K, Cloos PA, Christensen J, Pasini D, Rose S, et al. 2007. UTX and JMJD3 are histone H3K27 demethylases involved in HOX gene regulation and development. Nature 449:731-734.

2. De Santa F, Totaro MG, Prosperini E, Notarbartolo S, Testa G, Natoli G The histone $\mathrm{H} 3$ lysine-27 demethylase Jmjd3 links inflammation to inhibition of polycomb-mediated gene silencing. 2007.Cell 130:10831094.

3. Lan F, Bayliss PE, Rinn JL, Whetstine JR, Wang JK, et al. 2007. A histone H3 lysine 27 demethylase regulates animal posterior development. Nature 449:689-694

4. Lee MG, Villa R, Trojer P, Norman J, Yan KP, et al. 2007. Demethylation of $\mathrm{H} 3 \mathrm{~K} 27$ regulates polycomb recruitment and $\mathrm{H} 2 \mathrm{~A}$ ubiquitination. Science 318:447-450.

5. Kouzarides T. 2007. Chromatin modifications and their functions. Cell 128:693-705.

6. Barski A, Cuddapah S, Cui K, Roh TY, Schones DE, et al. 2007. Highresolution profiling of histone methylations in the human genome. Cell 129:823-837.

7. Bernstein BE, Mikkelsen TS, Xie X, Kamal M, Huebert DJ, et al. A bivalent chromatin structure marks key developmental genes in embryonic stem cells. 2006.Cell 125:315-326.

8. Bernstein BE, Kamal M, Lindblad-Toh K, Bekiranov S, Bailey DK, et al. 2005. Genomic maps and comparative analysis of histone modifications in human and mouse. Cell 120:169-181.

9. Lee TI, Jenner RG, Boyer LA, Guenther MG, Levine SS, et al. 2006. Control of developmental regulators by Polycomb in human embryonic stem cells. Cell 125:301-313.

10. Schwartz YB, Pirrotta V. 2007. Polycomb silencing mechanisms and the management of genomic programmes. Nat Rev Genet 8:9-22.

11. Kmita M, Duboule D. 2003. Organizing axes in time and space; 25 years of colinear tinkering. Science 301:331-333.

12. Simeone A, Acampora D, D'Esposito M, Faiella A, Pannese M, et al. 1989. Posttranscriptional control of human homeobox gene expression in induced NTERA-2 embryonal carcinoma cells. Mol Reprod Dev 1:107115.

13. Marlétaz F, Holland LZ, Laudet V, Schubert M. 2006. Retinoic acid signaling and the evolution of chordates. Int J Biol Sci 2:38-47.

14. Deschamps J, van Nes J. 2005. Developmental regulation of the Hox genes during axial morphogenesis in the mouse. Development 132: 2931-2942.

15. Schuettengruber B, Chourrout D, Vervoort M, Leblanc B, Cavalli G. 2007. Genome regulation by polycomb and trithorax proteins. Cell 128:735745.

16. Rea S, Eisenhaber F, O'Carroll D, Strahl BD, Sun ZW, et al. 2000. Regulation of chromatin structure by site-specific histone H3 methyltransferases. Nature 406:593-599.
17. Fischle W, Wang $Y$, Jacobs SA, Kim Y, Allis CD, Khorasanizadeh S. 2003. Molecular basis for the discrimination of repressive methyl-lysine marks in histone $\mathrm{H} 3$ by Polycomb and HP1 chromodomains. Genes Dev 17:1870-1881

18. Cao R, Tsukada Y, Zhang Y. 2005. Role of Bmi-1 and Ring1A in H2A ubiquitylation and Hox gene silencing. Mol Cell 20:845-854

19. Ringrose L, Rehmsmeier M, Dura JM, Paro R. 2003. Genome-wide prediction of Polycomb/Trithorax response elements in Drosophila melanogaster. Dev Cell 5:759-771.

20. Bracken AP, Dietrich N, Pasini D, Hansen KH, Helin K. 2006. Genomewide mapping of Polycomb target genes unravels their roles in cell fate transitions. Genes Dev 20:1123-1136.

21. Boyer LA, Plath K, Zeitlinger J, Brambrink T, Medeiros LA, et al. 2006 Polycomb complexes repress developmental regulators in murine embryonic stem cells. Nature 441:349-353.

22. Schwartz YB, Kahn TG, Nix DA, Li XY, Bourgon R, et al. 2006. Genomewide analysis of Polycomb targets in Drosophila melanogaster. Nat Genet 38:700-705.

23. Tolhuis B, de Wit E, Muijrers I, Teunissen H, Talhout W, et al. 2006. Genome-wide profiling of PRC1 and PRC2 Polycomb chromatin binding in Drosophila melanogaster. Nat Genet 38:694-699.

24. Terranova R, Agherbi H, Boned A, Meresse S, Djabali M. 2006. Histone and DNA methylation defects at Hox genes in mice expressing a SET domain-truncated form of MII. Proc Natl Acad Sci USA 103:6629-6634.

25. Glaser S, Schaft J, Lubitz S, Vintersten K, van der Hoeven F, et al. 2006. Multiple epigenetic maintenance factors implicated by the loss of MII2 in mouse development. Development 133:1423-1432.

26. Klymenko T, Müller J. 2004. The histone methyltransferases Trithorax and Ash1 prevent transcriptional silencing by Polycomb group proteins. EMBO Rep 5:373-377.

27. Bernstein BE, Humphrey EL, Erlich RL, Schneider R, Bouman P, et al. 2002. Methylation of histone H3 Lys 4 in coding regions of active genes. Proc Natl Acad Sci USA 99:8695-8700

28. Schuebeler D, MacAlpine DM, Scalzo D, Wirbelauer C, Kooperberg C et al. 2004. The histone modification pattern of active genes revealed through genome-wide chromatin analysis of a higher eukaryote. Genes Dev 18:1263-1271.

29. Rinn JL, Kertesz M, Wang JK, Squazzo SL, Xu X, et al. 2007. Functional demarcation of active and silent chromatin domains in human HOX loci by noncoding RNAs. Cell 129:1311-1323.

30. Ringrose L, Paro R. 2007. Polycomb/Trithorax response elements and epigenetic memory of cell identity. Development 134:223-232.

31. Tsukada $Y$, Fang J, Erdjument-Bromage $\mathrm{H}$, Warren ME, Borchers $\mathrm{CH}$ et al. 2006. Histone demethylation by a family of JmjC domain-containing proteins. Nature 439:811-816

32. Anand R, Marmorstein R. 2007. Structure and mechanism of lysine specific demethylase enzymes. J Biol Chem 282:35425-35429.

33. Shi Y. 2007. Histone lysine demethylases: emerging roles in development, physiology and disease. Nat Rev Genet 8:829-833.

34. Issaeva I, Zonis Y, Rozovskaia T, Orlovsky K, Croce CM, et al. 2007 Knockdown of ALR (MLL2) reveals ALR target genes and leads to alterations in cell adhesion and growth. Mol Cell Biol 27:1889-1903.

35. Wysocka J, Swigut T, Milne TA, Dou Y, Zhang X, et al. 2005. WDR5 associates with histone $\mathrm{H} 3$ methylated at $\mathrm{K} 4$ and is essential for $\mathrm{H} 3 \mathrm{~K} 4$ methylation and vertebrate development. Cell 121:859-872.

36. Rodriguez I. 2007. Odorant and pheromone receptor gene regulation in vertebrates. Curr Opin Genet Dev 17:465-470.

37. Dollé $P$, Izpisúa-Belmonte JC, Falkenstein $H$, Renucci A, Duboule D. 1989. Coordinate expression of the murine Hox-5 complex homoeoboxcontaining genes during limb pattern formation. Nature 342:767-772.

\section{BioEssays $\mathbf{3 0 . 3}$}

